\title{
Malignancies Associated with Treatment of Rheumatic Diseases - to be or not to be
}

Sur M Lucia ${ }^{1}$, Sur Genel ${ }^{1,2 *}$, Floca Emanuela ${ }^{1}$ and Sur Daniel ${ }^{1}$

${ }^{1}$ University of Medicine and Pharmacy, Iuliu Hatieganu, Cluj-Napoca, Romania

${ }^{2}$ Emergency Clinical Hospital for Children, Cluj-Napoca, Romania

\begin{abstract}
Malignancies associated with rheumatic diseases are more common than healthy individuals. What is actually the cause of increased malignancies in rheumatic diseases: autoimmunity, inflammation, immune regulation deficits? There was no a clear answer, but malignancies associated with rheumatic diseases is a certainty. Medication is also involved in the development of malignancies. Therefore we decided to address the involvement of rheumatic diseases medication in malignancies development.
\end{abstract}

Keywords: Rheumatic Diseases; Medication; Malignancy

\section{Introduction}

The immnune system is a barrier against neoplasms. Treatment of rheumatic diseases is done with modulators of the immune system. Thus immunosuppressive therapy may favor malignant cell growth. Cumulative dose of immunomodulatory agents and long treatment increase the risk of cancer development $[1,2]$.

It is known that inflammation is a component in cancer initiation and progression and therefore the reduction of systemic inflammation may reduce cancer risk [3].

The association between several systemic autoimmune diseases and lymphoproliferative malignancies is compatible with the concept of chronic activation of $\mathrm{B}$ cells and $\mathrm{T}$ cells as a driving force for the development of cancer comorbidity [4].

\section{Methotrexate}

Methotrexate is an antimetabolite. By inhibiting dihydrofolate reductase it reduces the production of purine nucleotides that are essential in DNA synthesis and cell division [5].

There are no clear data to suggest a direct role of methotrexate in developing malignancies. There are some reports that suggest an increased risk of lymphomas. Risk factors are represented by intense immunosuppression and severe disease, and increased frequency of latent infection with Epstein-Barr virus [6].

\section{Cyclophosphamide}

Cyclophosphamide is an alkylating agent from the oxazophosphorine group. It is metabolised via the cytochrome P450 enzyme system. Its mechanism in the treatment of autoimmune diseases is not well known. In patients with rheumatoid arthritis, Cyclophosphamide acts by suppressing $\mathrm{T}$-helper cell function with prolonged reduction of $\mathrm{B}$ cells $[1]$.

Cyclophosphamide increases the risk of developing some kinds of cancers such as bladder cancer, lymphoma and leukemia. Bladder cancer which is the most common malignancy associated with Cyclophosphamide may occur many years after this medication. The risk of development of malignancies is related to long duration of treatment and higher total dose administered $[7,8]$.

\section{Azathioprine}

Azathioprine, a purine analogue, interferes with DNA synthesis which is necessary for growth and cell division [9].

Risk of malignancy associated with Azathioprine therapy is significant and depends on cumulative dose and duration of treatment. Oncologic side effects have included an increased risk of lymphoproliferative disorders, particularly malignant lymphoma. Concomitant use of Azathioprine with other immunosuppressive agents enhances the risk of developing neoplasia $[8,10]$.

\section{Cyclosporine}

Cyclosporine inhibits $\mathrm{T}$ cell activation and the generation of Tcell lymphokine production $[1,3]$.

There are no clear evidence to support the relationship between therapy with cyclosporine and developing malignancies in patients with rheumatic diseases. It is known that patients with organ transplantation may develop lymphoproliferative disorders [10].

\section{Leflunomide}

Leflunomide is a selective inhibitor of de novo pyrimidine synthesis. The active metabolite of leflunomide, A771726, is a immunosuppressive compound that has been shown to be an antiproliferative agent for mononuclear and T-cells [11].

Leflunomide therapy does not increase the risk of malignancy in patients with rheumatic diseases [6].

\section{Tumor necrosis factor inhibitors}

Biologic response modifiers are treatments that target cytokines or the regulation of $\mathrm{T}$ or $\mathrm{B}$ cells. TNF inhibitors are potent modulators of

*Corresponding author: Sur Genel, University of Medicine and Pharmacy, luliu Hatieganu, Cluj-Napoca, Romania, Tel: 0724504964; E-mail: surgenel@yahoo.com

Received October 03, 2013; Accepted April 26, 2014; Published May 03, 2014

Citation: Lucia SM, Genel S, Emanuela F, Daniel S (2014) Malignancies Associated with Treatment of Rheumatic Diseases - to be or ot to be. J Bioequiv Availab 6: 078-079. doi: 10.4172/jbb.1000184

Copyright: $\odot 2014$ Lucia SM, et al. This is an open-access article distributed unde the terms of the Creative Commons Attribution License, which permits unrestricted use, distribution, and reproduction in any medium, provided the original author and source are credited. 
Citation: Lucia SM, Genel S, Emanuela F, Daniel S (2014) Malignancies Associated with Treatment of Rheumatic Diseases - to be or ot to be. J Bioequiv Availab 6: 078-079. doi: 10.4172/jbb.1000184

inflammation, apoptosis and other processes. It is important that they can either inhibit or to promote cancer development [12].

Observational studies did not show an increased risk of malignancy associated with anti-TNF therapy for rheumatoid arthritis. However, there are meta-analyzes and randomized studies which show a link between treatment with anti-TNF agents such as Etanercept, Infliximab and Adalimumab, and increased risk of cancer development. The most common form of cancer is lymphoma. Only a few studies have found an increased risk of nonmelanoma skin cancer [13-15].

Association between the immunomodulatory agents and cancer development must take into account the following: severity of disease, increased risk of malignancy in patients with rheumatoid arthritis, and these patients also received immunomodulatory agents before starting therapy with anti-TNF agents [12].

\section{References}

1. Robert RR, Thomas AF, William T, et al. (2013) Clinical Immunology: Principles and Practice. Elsevier Health Sciences.

2. Joseph A1, Brasington R, Kahl L, Ranganathan P, Cheng TP, et al. (2010) Immunologic rheumatic disorders. J Allergy Clin Immunol 125: S204-215.

3. Gary SF, Ralph CB, Sherine EG, et al. (2012) Kelley's Textbook of Rheumatology, Vol 1. Elsevier Health Sciences.

4. Turesson C1, Matteson EL (2013) Malignancy as a comorbidity in rheumatic diseases. Rheumatology (Oxford) 52: 5-14.

5. Beresford MW (2011) Juvenile idiopathic arthritis: new insights into classification, measures of outcome, and pharmacotherapy. Paediatr Drugs 13: 161-173.
6. http://www.fda.gov

7. Kelly, Ramanan AV (2012) The principles of pharmacological treatment of juvenile idiopathic arthritis. Paediatrics and child healt 21:12.

8. Beyaert R1, Beaugerie L, Van Assche G, Brochez L, Renauld JC, et al. (2013) Cancer risk in immune-mediated inflammatory diseases (IMID). Mol Cancer 12: 98.

9. Ballestar E (2011) Epigenetic alterations in autoimmune rheumatic diseases. Nat Rev Rheumatol 7: 263-271.

10. Gaujoux-Viala C1, Smolen JS, Landewe R, Dougados M, Kvien TK, et al (2010) Current evidence for the management of rheumatoid arthritis with synthetic disease-modifying antirheumatic drugs: a systematic literature review informing the EULAR recommendations for the management of rheumatoid arthritis. Ann Rheum Dis 69: 1004-1009.

11. Cutolo M1, Bolosiu H, Perdriset G; LEADER Study Group (2013) Efficacy and safety of leflunomide in DMARD-naive patients with early rheumatoid arthritis: comparison of a loading and a fixed-dose regimen. Rheumatology (Oxford) 52: 1132-1140.

12. Gullick NJ1, Scott DL (2012) Drug therapy of inflammatory arthritis. Clin Med 12: 357-363.

13. Burmester GR1, Mease P, Dijkmans BA, Gordon K, Lovell D, et al. (2009) Adalimumab safety and mortality rates from global clinical trials of six immunemediated inflammatory diseases. Ann Rheum Dis 68: 1863-1869.

14. Lin J1, Ziring D, Desai S, Kim S, Wong M, et al. (2008) TNFalpha blockade in human diseases: an overview of efficacy and safety. Clin Immunol 126: 13-30.

15. Grivennikov SI1, Karin M (2011) Inflammatory cytokines in cancer: tumour necrosis factor and interleukin 6 take the stage. Ann Rheum Dis 70 Suppl 1: i104-108. 